Marquette University

e-Publications@Marquette

$12-1-2009$

\title{
Identity and Democracy: Linking Individual and Social Reasoning
}

John B. Davis

Marquette University, john.davis@marquette.edu

Solange Regina Marin

Accepted version.Development, Vol. 52, No. 4 (December 2009): 500-508. DOI. (C) 2009 Palgrave Macmillan. Used with permission. 
NOT THE PUBLISHED VERSION; this is the author's final, peer-reviewed manuscript. The published version may be accessed by following the link in the citation at the bottom of the page.

\title{
Identity and Democracy: Linking individual and social reasoning
}

\author{
John B. Davis \\ Department of Economics, Marquette University \\ Milwaukee, WI \\ Solange Regina Marin \\ Departamento de Ciências Econômicas, Universidade Federal de \\ Santa Maria
}

\begin{abstract}
Following Amartya Sen's approach, John Davis and Solange Regina Marin look at individual and social reasoning when examining the complex relationship between identity and democracy. They characterize democracy as a process of social or public reasoning that combines the individual reasoning of all citizens. Identity is explained in terms of personal identity, social identity, and individual identity. They argue that democracy in combining the individual reasoning of all citizens responds to individuals' different personal identity concerns and needs, reflects their shared social identity interests and goals, and accords them rights and responsibilities associated with their many different individual identities.
\end{abstract}

Keywords: freedom capabilities agency individual identity social identity Amartya Sen 
NOT THE PUBLISHED VERSION; this is the author's final, peer-reviewed manuscript. The published version may be accessed by following the link in the citation at the bottom of the page.

\section{I ntroduction}

Sen writes: 'Rationality is ... the discipline of subjecting one's choices - of actions as well as of objectives, values and priorities - to reasoned scrutiny' (Sen, 2000b: 4). To say what is rational for us to choose, we need to examine our underlying reasons, and also our objectives, values, and priorities. Or, we need to determine whether our reasons for acting are 'really sustainable' where this includes 'the critical sustainability' of our objectives, values, and priorities (Sen, 2007). But how does one scrutinize one's objectives, values, and priorities? Sen does not believe this goes on in a personal vacuum with the individual cut off from others. Yet, if we engage in selfexamination of our reasons for acting, we are somehow independently responsible for our choices. How are these two sides to determining 'the critical sustainability' of our objectives, values, and priorities reconciled?

In this paper, we examine these questions in relation to individual and social reasoning, interpreted in terms of the relationship between identity and democracy. Democracy is understood as a process of social reasoning, which combines the individual reasoning of all citizens. Identity is seen in terms of personal identity, social identity, and individual identity. Democracy as a process of social reasoning combines the individual reasoning of all citizens, responds to individuals' different personal identity concerns, reflects their shared social identity interests and goals, and accords them rights and responsibilities associated with their different individual identities.

\section{Democracy}

Sen's capability perspective is an approach for evaluating a person's well-being, which has its own philosophical justification of the choice of weights of indicators of functionings and capabilities. According to Deneulin and Stewart (2002), Sen justifies them by an evaluative exercise. He proposes a pluralist and contextual account for assessing people's well-being, allowing for democratic processes in the selection of functionings. He does not prescribe a list of these; every evaluative exercise requires selection by an 'act of reasoning' (Robeyns, 2000: 14). 
A person is not only an entity that can enjoy one's own consumption, experience and appreciate one's welfare, and have one's goals, but also an entity that can examine one's value and objectives and choose in the light of those values and objectives. (Sen, 2002b: 36)

Sen's argument makes political and liberal rights important to the process of reasoning and self-scrutiny. He (1999b) argues that in regard to the relationship between democracy and economic growth the important issue is the impact of democracy and political freedoms on the lives and capabilities of citizens. It is relevant to examine the connection between political and civil rights, on the one hand, and the prevention of major disasters, on the other, because political and civil rights give people the opportunity to draw attention to general needs, and demand appropriate public action (Sen, 1999b: 150).

The demand for appropriate public action is related to understanding individuals as agents. Greater freedom enhances people's ability to help themselves and influence the world, and this is central to economic development (Sen, 1999b: 18). The term 'agent' is used to mean someone who acts and brings about change, and whose achievements can be judged in terms of her own values and objectives, whether or not we assess them in terms of external criteria as well (Sen, 1999b: 19).

One of Sen's strongest arguments for political freedom is the opportunity it gives citizens to discuss, debate, and participate in the selection of values in the choice of priorities. Sen (1999b: 153) emphasizes that political and civil rights, especially those related to guaranteeing open discussion, debate, criticism, and dissent, are central to the process of generating informed and reflective choice. The social choices individuals make allow for social value formation. The exercise of freedom is mediated by values, but values in turn are influenced by public discussion and social interaction, which are themselves influenced by participatory freedoms. Each of these connections deserves careful scrutiny (Sen, 1999b: 9). Social value formation thus relies also on democracy, free public media, and basic

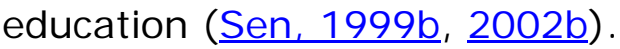


NOT THE PUBLISHED VERSION; this is the author's final, peer-reviewed manuscript. The published version may be accessed by following the link in the citation at the bottom of the page.

Sen's connection between political freedom and economic development invites one to consider what can be understood by democracy and its relation to individuals' agency. For Sen (1999a), we must not identify democracy with majority rule alone, as it has many complex demands, including voting and respect for election results, but also requires the protection of liberties and freedoms, respect for legal entitlements, and guaranteeing free discussions and uncensored distribution of news and fair comment. Even elections can be defective if they occur without giving different sides adequate opportunity to present their respective cases, or without giving the electorate freedom to obtain news and to consider competing views.

For Sen (1999a), democracy makes three distinct contributions: (i) it enriches individual lives through more freedom (involving political and civil rights); (ii) it provides political incentives to rulers to respond positively to the needs and demands of people; and (iii) the process of open dialogue and debate democracy helps in the formation of values and priorities, and this constructive function of democracy is very important for equity and justice as well as efficiency.

The process of decision-making through discussion enhances information about a society's and individuals' priorities, and those priorities respond to public deliberation. Sen (2003: 29) emphasizes that from the perspective of public reasoning, democracy gives a central place to guaranteeing free public discussion and deliberative interactions in political thought and practice. The value of public reasoning applies to reasoning about democracy itself. It is good that the practices of democracy have been sharply scrutinized in the literature on world affairs, for there are identifiable deficiencies in the performance of many countries possessing standard democratic institutions. Not only is public discussion of these deficiencies an effective means of trying to remedy them, but this is how democracy in the form of public reasoning is meant to function. In this sense, the defects of democracy demand more democracy, not less (2003: 34).

Sen (2005b) believes public reasoning: (i) involves respect for pluralism and tolerance for different points of view and lifestyles; (ii) demands an open public discussion of issues of common concern; and (iii) encourages political commitment and participation of people in public action for the transformation of society. There are reasons for 
Sen's life-long engagement and confidence in democracy, which are explained by three major contributions democracy makes to a country. First, as political freedom is an important freedom, the freedom to participate, to speak, and to vote is part and parcel of human freedom we have reason to value. Second, a democratic political system is instrumentally important, because it gives rulers incentives to respond to problems and predicaments of the public (the government must take a note of opposition criticism as well as possible electoral defeat), and because information becomes more easily available and shared with democratic practice. Third, through allowing and encouraging public discussion, democratic political systems help the formation of values.

Sen (2002a: 15) believes that participation not only has an instrumental role but also an intrinsic value for the quality of life. Being able to do something through political action - for oneself or others - is one of the elementary freedoms people have reason to value. Sen (2002a: 27) emphasizes that democracy is not the same thing as majority rule, as democratic rights include the protection of freedom of speech and other forms of participation as well as safeguarding of minority rights. Beyond that, it is worth noting that the process of public discussion and participatory interaction lead citizens to take an interest in the lives of each other.

\section{I dentity}

We distinguish three concepts of identity - personal, social, and individual. We compare these identity concepts in pair-wise fashion primarily to explain the relationship between personal identity and social identity. Sen's own emphasis is on social identity (1999c, 2006), though it can be argued he also reasons in terms of something like personal identity (Davis, 2007). Our starting point is also social identity, since we believe the individual in economics needs to be understood as socially embedded rather than atomistic (Davis, 2003). As the individual is always social, personal identity must be understood in terms of social identity. Thus we first suppose that individuals have social identities, and develop the other two identity concepts from this. 


\section{Social identity and individual identity}

Social identity is the idea of individuals' identification with others - other individuals or social groups. In the first case, social identity involves an individual-individual relationship, as in identifying with particular friends, family members, etc. In the second case, social identity is an individual-group relationship, as in identifying with groups according to such things as language, ethnicity, religion, work, etc.

Whether social identity takes the individuals (or relational) form or the group form, individuals' identification with others has different senses depending on who is responsible for the identification. Individuals themselves can identify with others, or can be identified with others by third parties. Thus, there are four types of social identity: (1) individuals themselves identify with other individuals; (2) individuals themselves identify with groups; (3) individuals are identified with others by third parties; and (4) individuals are identified with groups by third parties. Examples are: (1) a person identifies with a sick friend; (2) an immigrant identifies with a native language group; (3) social service workers socially identify individuals according to family relationships; and (4) statisticians socially identify individuals according to race and ethnicity.

Analyzing how individuals identify with others raises complex psychological issues, which we put aside here. When individuals are identified with others by third parties, this identification is systematic and public, as the third parties concerned are relatively enduring social entities such as government, market institutions, media and popular discourse, and social science. Important emphasis in this third party construction of individuals' social identities concerns the group form, in that these socially constructed social identities are generally built around social group categories, or generalizations about collections of individuals, that are functional to the social organization of increasingly complex societies. But they also result from social conflict and the efforts of individuals and groups to exercise power over one another.

Individual identity is a correlate of the third party-social group concept of social identity used to describe the representative individual. Individual identity thus understood is a matter of the 
individual falling within a class of individuals corresponding to a social group category, resulting from ascription of characteristics of the class to the individual. Individual identity concepts created for social organizational reasons include: tax payer, degree holder, pension earner, medical patient, and citizen. Individual identity concepts generated from social conflict and efforts to exercise power include: trade union member, immigrant, welfare recipient, insider trader, and terrorist.

An important dimension of third party concepts of social identity and individual identity is the need for stability in their application. Social group categories are designed to pick out patterns of social life believed stable. Tax and pension systems, practices of discrimination and methods of social exclusion, medical service delivery, penal codes, personnel files and educational records, etc. function as social tools used to pick out stable patterns of social behaviour. This requires consistency in the assignment of individuals to social groups. Thus, though many of a person's income and employment characteristics change over time, that person, nonetheless, retains an unchanging individual identity as taxpayer and future pension recipient. Or, though a person's health states change over a lifetime, that person's medical history individual identity is not to be confused with another person's.

Accompanying most social group categories, there are 'continuity' tracking technologies that operationalize individual identities: names, number assignments, individualized records of all kinds, family descent, curriculum vitae, photographs, biometric measures (fingerprints, DNA identification, dental records, brain scans, iris scans), surveillance, and incarceration or institutionalization. As social group categories allow for managing large, heterogeneous populations of individuals according to functional relationships believed to obtain between them, these tracking tools provide practical working systems for these categories' consistent application. Philosophically, social group categories require tools to successfully re-identify and individuate individuals in terms of the social group characteristics that consistently and uniquely apply to them (Davis, 2003). 


\section{Individual identity and personal identity}

We assume that individuals are not only objects in the sense defined by third parties, but following Sen, also agents or subjects. We further assume that being an agent or subject is part of the concept of personal identity. Individual identity is purely an object characterization of individuals in terms of being a member of a category or class of things, and not a concept of personal identity. As individual identity is derived from the third party-social group concept of social identity, it leaves out what the first three types of social identity contribute to understanding personal identity, specifically, the role played by individuals themselves in identifying with others (individuals or groups), and the role played by their being identified with other individuals by third parties.

This does not imply that people's individual identities are not a part of their personal identities. We suppose personal identity incorporates all four aspects of an individual's social identity, including the many group membership individual identities ascribed to individuals by third parties, since an individual's personal identity does not exist in a social vacuum apart from the characteristics society attributes to the individual as a member of social groups. This also applies to the type of social identity produced when third parties identify individuals with other individuals, as in the social worker case. That others judge a person to have close social relationships to others, and see this as part of that person's social identity is not irrelevant to a person's personal identity. Generally, what others think of a person's relationships to individuals and groups influences what the person thinks about those relationships. Thus, we say that an individual's personal identity incorporates their own identification with other individuals and groups, as influenced by what third parties think about this, and all four types of social identity enter into personal identity.

We focus only on the relationship between individual identity and personal identity, or the rows of the table. First consider the difference between the two third party ascriptions of social identity. With type 3, the social worker case, a person's social identity is a matter of an individual-individual(s) relationship, or social identity is relational. With type 4 , however, the person is simply a member of a 
class, and only a representative member at that. The statistician who ascribes a racial or ethnic social identity to a person is only interested in an abstract, non-relational property the individual has as a member of a class of such individuals. In effect, type 4 social identity reduces the person to an abstract object. $\underline{1}$

Type 4 social identity can be seen as the polar opposite of the case of identifying with a sick friend, type 1 , since there the individual determines the identification with the other, and this is an individualto-individual or relational kind of identification rather than identification with a social group category. Accordingly, on the assumption that idea of being an agent or subject is part of the concept of personal identity, individuals are the most responsible for their personal identities in type 1 cases, where they determine their identification with others and do so in interaction with others, and least responsible in type 4 cases.

Yet, all four types of social identity somehow enter into personal identity, and must include this especially strong polarity of being both a subject and a third party object. For example, a person can identify with a set of friends, and regard it as irrelevant they are of another racial or ethnic background (type 1 ), yet the social identity which the government statistician might emphasize may be restricted to the person's own racial or ethnic background or other groups' characteristics 'officially' assigned to the individual (type 4). Real world examples are more complicated, since the government statistician is only one of many third parties who assign individuals social group identities, and these group identities are often inconsistent and competing, particularly where power is contested. Thus just considering type 4 social identity alone, inherent within individuals' personal identities, there exist many social identity conflicts according to competing social group assignments individuals must reconcile. If we add in the type 2 and type 3 social identity cases, the general picture is: personal identity is constituted within a social identity structure replete with conflicting demands and expectations individuals need to organize for their lives to be coherent.

Thus personal identity includes the idea of being an agent, and individuals need to be seen as active in negotiating their complex and conflicting social identities to achieve some level of unity as an 
individual. Broadly, we define personal identity as individuals' own way of negotiating and organizing all their social identities. This view links up with two important dimensions of Sen's thinking about individuals. It sees individuals as agents, and requires individuals to be selfscrutinizing or reflexive. Thus a fuller definition of personal identity is an individuals' active and reflexive negotiation of their complex social identities.

\section{Personal identity and social identity}

Personal identity and social identity are not opposed (as with atomistic individual conceptions), but for socially embedded individuals are defined in terms of one another. Personal identity is defined in terms of social identity, or how individuals relate to others, yet not reducible to it since it emphasizes the idea of the individual as a reflexive agent. Social identity in its different dimensions is always about the identity of individuals, yet not reducible to this, since it includes third party determination.

If we associate individual reasoning and social reasoning with the two rows of Table 1, they are not seen as opposed either. Individual reasoning and social reasoning, of course, include more than just issues of identity. Yet questions of identity are surely paramount, since they arise whenever individuals and society say what individuals are, and whose reasoning combines to produce social reasoning.

Table 1. Types of social identity with examples

\begin{tabular}{|c|c|c|}
\hline Who determines & \multicolumn{2}{|c|}{ I dentification with } \\
\hline & Individuals & Groups \\
\hline Individuals themselves & (1) Sick friend & (2) Native language \\
\hline Third parties & (3) Social service workers & (4) Statisticians \\
\hline
\end{tabular}

Here we focus on claims about well-being, and understand them in terms of individual and social reasoning as they relate to the concepts of personal and social identity. There are two approaches to individual well-being in recent economics, often taken to be opposed. The happiness or subjective well-being approach (e.g., Diener and Seligman, 2003; Kahneman and Krueger, 2006) emphasizes 
individuals' own assessment of their well-being (usually in hedonistic terms), and the quality of life or objective well-being approach (e.g., Sen, 1993; Offer, 2003) emphasizes socially determined requirements for a good life (such as capabilities). That individual and social reasoning are related suggests we should combine these different perspectives. We use our identity framework to do this, and also demonstrate the connection between personal identity and social identity.

In the identity framework, the strong polarity between an individual being a subject and being a third party object replicates the opposition between subjective and objective approaches to individual well-being. But as personal identity is a matter of managing the different dimensions of social identity, individual well-being also has both subjective and objective dimensions. Beginning with the objective dimension, a person's individual identities (type 4 social identity) are due to the efforts of third party experts to establish applicable categories of well-being. For example, consider those responsible for the creation of the Human Development Index (HDI). Their aim is to establish such categories of well-being as literacy, income, health, shelter, etc. that average individuals should achieve as capabilities. Public policy then works to change institutions and create access to resources to realize these 'average capabilities'.

But now consider the subjective dimension of individual wellbeing. As Sen emphasizes, different individuals use resources in different ways. Further, as people have many capabilities, how they combine any given set of individual identities in the form of a set of 'average capabilities' that applies to them varies for each individual according to circumstances. Thus, personal identity in regard to wellbeing is a matter of how individuals negotiate their many 'average capabilities' individual identities (here only emphasizing the strong polarity between being a subject and being an object of third party reasoning). This brings in the subjective side of well-being in terms of individuals' own assessment of their well-being to bear on the issue of individual well-being (though not in the hedonistic happiness sense).

Do individuals' assessments of their well-being influence third party experts' assessment of individual well-being? Experts are subjects too, so when not in that guise, they are also concerned about 
their personal identities in the space of social identity, and accordingly must reason about the methodology of the social categories with which they operate. This large topic, however, goes beyond our focus on personal identity and social identity.

In sum, the advantages of casting individual and social reasoning in terms of personal and social identity are that we explain this reasoning in terms of the dual nature of human beings as subjects and objects, and make it possible to refine our normative thinking in economics, as in the characterization of individual well-being.

\section{Democracy and identity}

Social reasoning takes many forms as regards particular aspects of social-political systems and with respect to systems taken as a whole. In addressing democracy we take the latter stance, and characterize social reasoning like Sen as public reasoning. Sen takes public reasoning as a defining feature of democracy, which he takes as a system of open engagement and exchange in political decisionmaking. How, then, does democracy relate to identity?

The previous analysis treats personal and social identity as interrelated. Individuals pursue personal identities framed by their social identities, and influence the framing of social identities, thus reflecting their dual nature as subjects and objects. Democracy, as a form of social reasoning, frames individuals' political social identities, while as a system of public reasoning it responds to and exhibits individuals' negotiation of their many social identities in pursuit of their respective personal identities.

On the one hand, as a system of social identity framing, democracy invests individuals with political and civil rights, creating the social category of 'citizen' and a corresponding individual identity for each individual framed in terms of these rights. These rights define a scope of activity applying to all individuals who fall into the social group category 'citizen'. That a right applies to all falling within this category means that the principle of equality in a political system is an outcome made possible in part by third party determination of one aspect of individuals' social identity. 
On the other hand, just as Sen reminds us that different individuals use resources in different ways, so different individuals exercise their 'citizen' political and civil rights in different ways as they negotiate their many social identities and associated individual identities. Democracy itself, then, is framed by individuals as a process of open engagement and exchange that allow individual exercise of political and civil rights. This influences society's determination of what rights and capabilities individuals on average ought to have. For example, if individuals have the right to religious freedom, but many individuals are non-believers, the right to religious freedom is interpreted to include non-belief. 'Citizen' rights are thus like the 'average capabilities' of the HDI. Their exercise both determines which individual functionings make up the political side of individuals' social identities, and contributes to the social determination of which rights and capabilities individuals on average have.

\section{Essential capabilities}

We turn to the issue of essential capabilities. Nussbaum (2000, 2003) has argued that the capability approach requires a list of central human capabilities. Sen has argued one cannot fix such a list, because we cannot anticipate what future individuals will value, and it would be a denial of democracy to do so (2005a). Robeyns (2003) strikes a middle ground by recommending a procedural approach to selecting capabilities by proposing criteria for capability selection. We agree with Nussbaum that having a conception of human flourishing is important, with Sen that this needs to be determined in a democratic setting, and with Robeyns that normative criteria exist for different societies' selection of capabilities. Our view is based on the relationship between individual and social reasoning and between identity and democracy.

As argued, individuals pursue personal identities framed by their social identities, and thus combine individual and social reasoning. The pursuit of personal identity, however, is surely a conception of human flourishing, as it involves individuals determining what they believe best for them. At the same time, what exactly this involves must remain open-ended as individuals' collection of social identities and forms of interaction changes over time. Nonetheless in democratic societies with their systems of public reasoning, procedural criteria for 
the way individual and social reasoning combine exist in the form of strategies for open engagement and exchange. Systems of public reasoning, then, maximize the capability space, and allow individuals the opportunities to acquire the functionings they determine are best for them. Thus Nussbaum's vision strikes us as correct, Sen is right about the open-ended character of capability selection, and Robeyns captures the need for criteria for doing so. We summarize our view by labelling personal identity the central capability of individuals. By this we mean that it is the one capability that must be assumed to assure both human flourishing and open-endedness in individuals' selection of other capabilities.

\section{Conclusion}

Sen emphasizes the importance of subjecting one's choices of actions, objectives, values, and priorities to reasoned scrutiny. Individuals do not do this in isolation and yet a reasoned scrutiny of one's actions, objectives, values, and priorities is a matter of selfscrutiny. These seemingly opposed ideas make sense if we begin by thinking of individuals as social. We explain social individuals as individuals who pursue personal identities framed by their social identities. Neither concept is reducible to the other, nor can either be eliminated. At the same time, the identity framework used here shows individual well-being has subjective and objective dimensions. This makes it possible to talk about social individuals as individual beings, while it reproduces the tension between the individual and the social within the individual in individuals' need to organize and manage their many social identities. This tension and the dynamic of choice and action to which it gives rise in individuals and societies precludes our saying what capabilities ought to be thought essential - with one exception. If individuals are constrained in pursuing personal identities, their social side engulfs them. Open democratic societies, however, can prevent this, and permit individual human flourishing in the form of the exercise of a wide range of human capabilities.

\section{Footnotes}

${ }^{1}$ In case 3 , in contrast, individuals have specific relations to other individuals, the understanding of which requires knowledge of their 
NOT THE PUBLISHED VERSION; this is the author's final, peer-reviewed manuscript. The published version may be accessed by following the link in the citation at the bottom of the page.

particular characteristics. We do not further discuss this relational aspect of social identity (casesland 3) here.

\section{References}

Davis, J ohn (2003) The Theory of the Individual in Economics: Identity and value, London: Routledge.

Davis, John (2007) 'Identity and Commitment: Sen's fourth aspect of the self', in Fabienne Peter and Bernhard Schmid (eds) Rationality and Commitment, Oxford: Oxford University Press.

Deneulin, Severine and Frances Stewart (2002) 'Amartya Sen's Contribution to Development Thinking', Studies in Comparative International Development 37 (2): 61-70.

Diener, Edward and Martin Seligman (2003) 'Beyond Money: Toward an economy of well-being', Psychological Science in the Public Interest 5: $1-31$.

Kahneman, Daniel and Alan Krueger (2006) 'Developments in the Measurement of Subjective Well-Being', J ournal of Economic Perspectives 20 (1): 3-24.

Nussbaum, Martha (2000) Women and Human Development: The capabilities approach, Cambridge: Cambridge University Press.

Nussbaum, Martha (2003) 'Capabilities as Fundamental Entitlements: Sen and social justice', Feminist Economics 9 (2-3): 33- 59.

Offer, Avner (2003) 'Economic Welfare Measurements and Human Wellbeing', in Paul David and Mark Thomas (eds.) The Economic Future in Historical Perspective, Oxford: Oxford University Press.

Robeyns, Ingrid (2000) 'An Unworkable Idea or a Promising Alternative? Sen's Capability Approach Re-examined, July 15, 2007', Discussion paper, Center for Economic Studies, University of Leuven http://www. ingridrobeyns.nl/Ac publ list.html, accessed 15 July 2007.

Robeyns, Ingrid (2003) 'Sen's Capability Approach and Gender I nequality: Selecting relevant capabilities', Feminist Economics 9 (2-3): 61-92.

Sen, Amartya (1993) 'Capability and Well-being', in Martha Nussbaum and Amartya Sen (eds.) The Quality of Life, Oxford: Clarendon Press.

Sen, Amartya (1999a) 'The Value of Democracy', The World Bank Institute. Development Outreach. Summer 1999 - Putting knowledge to work for development, http://www1. worldbank.org/devoutreach/summer99/article.asp?id=3, accessed 17 February 2007.

Sen, Amartya (1999b) Development as Freedom, New York: Anchor Books. Sen, Amartya (1999c) Reason before Identity, New Delhi: Oxford University Press. 
NOT THE PUBLISHED VERSION; this is the author's final, peer-reviewed manuscript. The published version may be accessed by following the link in the citation at the bottom of the page.

Sen, Amartya (2002a) 'Democratic Practice and Social Inequality in India', J ournal of Asian and African Studies 37 (2): 6-37.

Sen, Amartya (2002b) Rationality and Freedom, Cambridge: The Belknap Press of Harvard University Press.

Sen, Amartya (2003) 'Why Democratization is Not the Same as Westernization: Democracy and Its Global Roots', New Republic 6 October 2003, Vol. 229, no. 14: 28-36.

Sen, Amartya (2005a) 'Human Rights and Capabilities', J ournal of Human Development 6 (2): 151-166.

Sen, Amartya (2005b) 'Indian Democracy and Public Reasoning', Front Line: India's National Magazine 22 (4).

Sen, Amartya (2006) Identity and Violence: The illusion of destiny, New York: Norton.

Sen, Amartya (2007) 'Rational Choice: Discipline, brand name and substance', in Bernhard Schmid and Fabienne Peters (eds.) Rationality and Commitment, Oxford: Oxford University Press.

Development, Vol 52, No. 4 (December 2009): pg. 500-508. DOI. This article is (C Palgrave Macmillan and permission has been granted for this version to appear in e-Publications@Marquette. Palgrave Macmillan does not grant permission for this article to be further copied/distributed or hosted elsewhere without the express permission from Palgrave Macmillan. 